\title{
The Impact Of School Climate On School Outcomes
}

J. Eric Tubbs, Kennesaw State University, USA

Mary Garner, Kennesaw State University, USA

\begin{abstract}
The purpose of this article is to provide insight into an elementary school whose climate issues appear to plague and impact it's performance as measured by it's Annually Yearly Progress (AYP). The Northwest Georgia elementary school is located in a rural school system approximately 50 miles northwest of Atlanta, Georgia. A review of the literature suggests school climate can affect many areas and people within schools. It further suggests that positive interpersonal relationships and optimal learning opportunities in all demographic environments can increase school achievement levels and reduce maladaptive behaviors (McEvoy \& Welker, 2000). Providing a positive and supportive work environment and climate for faculty and staff, more often than not, improves faculty, staff and student performance (Freiberg, 1998). An in-depth analysis of the environment of the school in question suggests a lack of faculty and staff respect for administration, a hostile work environment, and overall low morale. Deep frustration and anger on the part of faculty and staff were apparent in a substantial number of written responses to open-ended questions. Although responses to work environment and administration were split along mean scores, the overall data indicate that the status quo cannot continue without continued negative consequences. When half of the faculty and staff are dissatisfied with their work environment and administration, teaching and learning is almost certain to be negatively impacted. A Rasch analysis further supports recommendations.
\end{abstract}

Keywords: school climate, school effectiveness, school culture, teachers' morale, staff stability, and students' background

\section{A REVIEW OF RELATED LITERATURE}

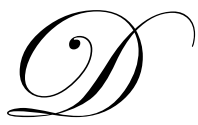

erived as a concept from the research on organizational climate and school effectiveness, school climate takes on many definitions and conceptualizations. Early on, the concept was viewed as something intangible but consequential to an organization and analogous to an individual's personality (Halpin \& Croft 1963). According to Hanna (1998), one can categorize the environmental quality of an organization in four dimensions: operations, climate, social system, and culture. Applied to schools, the operational dimension would refer to the physical and material aspects, such as the school building and school library.

The climate would be the average characteristics of the individuals in school, such as teachers' morale, staff stability, and students' background. The social system would be the formal and informal structures or rules that govern individuals' and groups' interactions in school. They include principal-teacher communication, participation of staff in decision making, students' involvement in decision-making, collegiality, and teacher-student relationships. Finally, the cultural dimension is concerned with values and belief systems, such as peer norms, expectation for success, and behavior management in schools. Based on this taxonomy, Ashby and Krug (1998) did a very thorough review based on over 200 references on school climate.

However, a closer examination of the major studies they reviewed revealed that most school-climate research focuses on the social system and cultural dimensions. Although these two elements are related to the 
physical characteristics and diversification of an organization, it is the intangible qualities of the school about which school-climate researchers are concerned.

Thus, school climate is viewed as part of the school environment associated with attitudinal and affective dimensions and the belief systems of the school that influence children's cognitive, social, and psychological development. School climate is reflected in the social interactions in and out of the classroom, and from the faculty lounge to the lunchroom (Ashby and Krug 1998). Because values, attitudes, beliefs, and communications are adult focused behaviors, researchers primarily rely on participants' perceptions to measure school climate and sometimes aggregate the participants' response to the level of interest, such as classroom or school (Griffith 2000).

\section{Academic Outcomes}

Previous studies have found school climate to exert significant influence over school performance. The most studied educational outcome of school climate is learning and academic achievement. A review of 40 major studies between 1964 and 1980, Kuperminc (2001) found over half of these studies reported effects of school climate on student achievement. High students achievement is associated with high teacher commitment or engagement, positive peer norms, an emphasis on group or team cooperation, high level of expectation held by teachers and administrators, consistency in administering rewards and punishments, consensus over curriculum and discipline, and clearly defined goals and objectives. Some of these relationships between school climate and student achievement remain significant after students' background characteristics are controlled (Kuperminc, et. al (2001). In fact, much of the observed variance in achievement that has been attributed to the school's composition may even be a result of school climate (McDill, et. al, 1969). In their study of effective schools summed up the aspects of school climate that are most strongly related to school outcomes: high expectations, orderly school environments, high morale, positive treatment of students, active and positive engagement of leadership, and positive social relationships in school.

\section{Factors That Influence Climate}

Positive school climate can be developed through assessment, analysis, leadership and professional learning communities, and carefully monitoring progress. Some schools assess the school climate as often as four times a year. One way to assess school climate, and then strive to improve it, is through periodic climate surveys. The survey should address school climate and, based on that, administrators can determine the current condition and decide whether the teachers' work environment or overall school climate needs to be monitored or maintained, or whether it needs intensive care (Keefe and Kelley, 1990). Attending to a school's climate does not happen overnight, nor without conflict. According to Freiberg (1998), "Perhaps there are schools that have made the transition to a professional learning community without conflict or anxiety, but are unaware of any. Disagreements and tension are to be expected. The question schools must face is not, 'How can we eliminate all potential for conflict as they go through this process?' but rather, 'How will we react when we are immersed in the conflict that accompanies significant change?'

Finally, research shows that school climate can affect many areas and people within schools. Consequently, research suggests that positive interpersonal relationships and optimal learning opportunities in all demographic environments can increase school achievement levels and reduce maladaptive behaviors (McEvoy and Welker, 2000).

These suggestions can be accomplished providing a positive and supportive work for faculty and staff through professional development and learning communities.

The elements that comprise a school's climate are extensive and complex. As a result, researchers support the following factors that influence school's climate (Christensen, et. al, 2006):

1. School vision and mission statement.

2. Faculty and staff work relationships.

3. Lines of communication. 
4. Principal's behavior and instructional leadership style.

5. Faculty and staff's feeling of trust and respect for leadership.(p. 74)

Clearly, school climate is multi-dimensional and influences many individuals. Additionally, school climate can significantly impact teacher behaviors and thereby influence the health of the school climate or create significant school performance barriers. Although this essential term has been researched for many years, a sole definition has yet to be formulated. However, in order to determine the nature and scope of Shane Elementary School's climate, the researcher defined school climate as "The atmosphere or ambience of an organization as perceived by its members" (Ehman, 1980). Additionally, an organization's climate is reflected in its structures, policies, and practices; the demographics of its membership; the attitudes and values of its members and leaders; and the quality of personal interactions. Furthermore, the result of behaviors within a workplace or learning environment, ranging from subtle to cumulative to dramatic, can influence whether an individual feels personally safe, listened to, valued, and treated fairly and with respect (Peterson and Skiba 2001).

\section{A NORTH WEST GEORGIA CLIMATE STUDY}

\section{Climate Impact}

Without a doubt a review of the literature suggests school climate can affect many areas and people within schools. Consequently, positive interpersonal relationships and optimal learning opportunities in all demographic environments can increase school achievement levels and reduce maladaptive behaviors (McEvoy \& Welker, 2000). By providing a positive and supportive work environment and climate for faculty and staff, more often than not, improves faculty, staff and student performance. Realizing that a serious morale problem existed in one their elementary schools, a Northwest Georgia School District requested a climate survey to determine the scope of the perceived problems. The district superintendent instructed his researcher to design a survey to determine the level of faculty and staff dissatisfaction toward their work environment and the school's climate.

\section{Rationale}

The purpose of this study was to identify school climate issues that appeared to exist in an elementary school and what impact it has on the school's performance as measured by it's Annual yearly Progress (AYP).

\section{Research Questions}

The researcher and school system sought to answer the following questions for this study:

1. What are faculty and staff's perceptions of their school's vision and mission?

2. What are faculty and staff's disposition toward their work environment?

3. How do faculty and staff view lines of communications within their school?

4. What are faculty and staff's perceptions of their principal's role as instructional leader?

5. What are faculty and staff's overall personal opinion of their school?

\section{Participants}

The target population for this study was a North West Georgia Elementary School. The elementary school is located in a rural school system located about 50 miles northwest of Atlanta, Georgia. The school system is a small County School District with about 6,500 students served by 190 certified and classified faculty and staff. Currently, the system has five elementary schools for students in kindergarten through fifth grade, two middle schools serving sixth through eighth grade, and 2 high schools serving ninth through twelfth grade; 56 percent of the principals are at the elementary level, twenty two percent are at the middle school level, and twenty two percent are at the high school level. This school system is operated by a seven member elected board. The superintendent is appointed by the board and the funding for each school is based on a full-time per pupil allocation. 
The demographic for the target elementary for this is Shane Elementary School (school name protected). Shane currently serves approximately 600 students in grades pre-k through $5^{\text {th }}$ grade. The school employs 42 faculty and staff, 31 or $75 \%$ are Caucasian, 4 or $9 \%$ are African American, and 6 or 15\% are Hispanic.

\section{Instrumentation}

The instrument for data collection in this study consists of 29 Likert scale questions and three open-ended questions that relate to faculty and staff disposition toward their overall school climate. The instrument was designed by Joseph and Associates (2007) with reference to current literature. The instrument was also divided into six major sections. The first section consisted of six demographic items. Sections II through V contained twenty-eight items in the form of a Likert-scale to determine Shane's faculty and staff's deposition regarding their and school's vision and mission, work environment, communication, administration and their personal opinions by their response to three open-ended questions in Section VI. The items in sections I through V of the instrument required respondents to select one of four expressions: Strongly Agree, Agree, Disagree, and Strongly Disagree. Each expression was assigned an appropriate weight to indicate the level of agreement or disagreement. Additionally, items in Sections II through $\mathrm{V}$ were scored four to one with four being the highest score representing strong favorable view regarding the item and one the lowest score representing a less than favorable view regarding the item.

Section VI contained three open-ended questions. Researchers traditionally employ a $10 \%$ rule: $10 \%$ of a population needs to mention a topic (in response to open-ended questions) in order to justify pursuing additional analyses. This researcher used a more conservative criteria, by considering $20 \%$ of the population needed to mention the topic in order justify pursuing additional analysis.

Internal consistency was determined by applying the Alpha Reliability Coefficient, which yielded an internal consistency reliability co efficiency for an overall survey instrument reliability of .89 . For the sub-scales of the investigative instrument the test yielded the following: (1) Vision and Mission Statement .80 , (2 Work Environment .88, (3) Communication .90, and (4) Administration .93. Hoy and Smith (2002) argue that whenever an instrument's reliability value is .60 or above, the instrument is considered reliable. Additionally, the researcher tested the significance of the four (4) above reliability coefficients at the .05 level. Each coefficient was found to be significant.

In order to further analyze data the Rasch Measurement Model was used (Bond \& Fox, 2001; Wilson, 2005). The Rasch model provides an item-level analysis of the survey questions. The nature of the model is discussed in the context of the findings in this study. The software Facets (Linacre, 2005) was used to apply a Rating Scale Rasch Model.

\section{Procedure}

All faculty and staff employed at Shane Elementary were identified and contacted. The established instrument developed for data collection was administered at a full faculty meeting. After reviewing the responses a follow up meeting was conducted by the superintendent to discuss survey findings, with in-depth questions, to further understand their disposition toward Shane Elementary School's climate.

\section{Data Analysis}

Quantitative and Qualitative data collected from the survey responses were divided into two major categories of facts and dispositions. They were summarized and analyzed through observation of descriptive data, frequencies, percentages, mean scores and topic and trend cited in responses to open-end questions. 


\section{FINDINGS}

\section{Demographics}

The descriptive analysis (See Table 1) 1 yielded $90.7 \%$ of respondents certified and $9.3 \%$ classified. Of the respondents, $100 \%$ were female, with 75\% Caucasian, 9\% African American and 15\% Hispanic. Additionally, the faculty and staff were divided into age categories of 30 or less, 31 to 35,36 to 40,41 to 45,46 to 50 , and 51 and above. The percent of participants who were identified in the above age categories, consecutively, were: 30 or less, $27.9 \%$ (12); 31 to $35,16.3 \%$ (7); 36 to $40,9.3 \%$ (4); 41 to $45,9.3 \%$ (4); 46-50, 11.6 (5), and; 51 and above $25.6 \%$ (11). Furthermore, $34.9 \%$ (15) of the respondents had 5 or fewer years, 20.9\% (9) had 6 to 10 years, 9.3\% (4) had 11 to 15 years, $14 \%$ (6) had 16 to 20 years, $4.7 \%(2)$ had 21 to 25 years, and $16.3 \%(n=7)$ of the teachers ha 25 years or more experience teaching.

Table 1

\begin{tabular}{|c|c|c|c|}
\hline \multicolumn{4}{|c|}{ Demographics } \\
\hline Variables & Frequency & Percent & Mean \\
\hline Position & & & 1.09 \\
\hline 1. Certified & 39 & 90.7 & \\
\hline 2. $\quad$ Classified & 4 & 9.3 & \\
\hline 3. Other & 0 & 0 & \\
\hline Total & 43 & 100 & \\
\hline Ethnicity & & & 1.90 \\
\hline 1. Afro. Amer. & 4 & 10 & \\
\hline 2. Caucasian & 31 & 75 & \\
\hline 3. Asian & 0 & 0 & \\
\hline 4. Hispanic & 6 & 15 & \\
\hline 5. Other & 0 & 0 & \\
\hline Total & 43 & 100 & \\
\hline Age & & & 3.37 \\
\hline 1. 30 or Less & 12 & 27.9 & \\
\hline 2. $31-35$ & 7 & 16.3 & \\
\hline 3. $36-40$ & 4 & 9.3 & \\
\hline 4. $41-45$ & 4 & 9.3 & \\
\hline 5. $46-50$ & 5 & 11.6 & \\
\hline 6. 51-Over & 11 & 25.6 & \\
\hline Total & 43 & 100 & \\
\hline Experience & & & 2.81 \\
\hline 1. $0-5$ yrs. & 15 & 34.9 & \\
\hline 2. 6-10 yrs. & 9 & 20.9 & \\
\hline 3. $11-15$ yrs. & 4 & 9.3 & \\
\hline 4. $16-20$ yrs. & 6 & 14.0 & \\
\hline 5. $21-25$ & 2 & 4.7 & \\
\hline 6. 25-Over & 7 & 16.3 & \\
\hline Total & 43 & 100 & \\
\hline
\end{tabular}

In the instrumentation design, the researcher and school officials set mean scores at 3.0 or above before category questions and research questions would be considered satisfactory. Descriptive data (See Table 2) yield an observed average mean score of 3.2, suggesting faculty and staff, overall, embrace their school's vision and mission, which satisfies research question (1). 
Table 2

\begin{tabular}{|c|c|c|c|c|c|c|c|c|c|c|c|}
\hline \multirow{2}{*}{\multicolumn{2}{|c|}{$\begin{array}{l}\text { Questions } \\
\text { Vision and Mission }\end{array}$}} & \multicolumn{2}{|c|}{$\mathrm{SA}=4$} & \multicolumn{2}{|c|}{$\mathbf{A}=\mathbf{3}$} & \multicolumn{2}{|c|}{$\mathbf{D}=\mathbf{2}$} & \multicolumn{2}{|c|}{ SD $=1$} & \multirow[b]{2}{*}{ Mean } & \multirow[b]{2}{*}{$\mathrm{N}$} \\
\hline & & $\mathrm{n}$ & $\%$ & $\mathrm{n}$ & $\%$ & $\mathrm{n}$ & $\%$ & $\mathrm{n}$ & $\%$ & & \\
\hline Q1 & School's vision is a shared vision & \multicolumn{2}{|c|}{$14 / 32.6$} & \multicolumn{2}{|c|}{$23 / 53.5$} & \multicolumn{2}{|c|}{$4 / 9.3$} & \multicolumn{2}{|c|}{$2 / 4.7$} & 3.1 & 43 \\
\hline Q2 & Principal communicates clear completing vision & \multicolumn{2}{|c|}{$16 / 37.2$} & \multicolumn{2}{|c|}{$22 / 51.2$} & \multicolumn{2}{|c|}{$3 / 7.0$} & \multicolumn{2}{|c|}{$2 / 4.7$} & 3.2 & 43 \\
\hline Q3 & How school objective and initiatives contribute & \multicolumn{2}{|c|}{$18 / 41.9$} & \multicolumn{2}{|c|}{$21 / 48.8$} & \multicolumn{2}{|c|}{$3 / 7$} & \multicolumn{2}{|c|}{$1 / 2.3$} & 3.3 & 43 \\
\hline Q4 & Motivated by school's vision to do my best & \multicolumn{2}{|c|}{$21 / 48.8$} & \multicolumn{2}{|c|}{$18 / 41.9$} & \multicolumn{2}{|c|}{$3 / 7$} & \multicolumn{2}{|c|}{$1 / 7$} & 3.4 & 43 \\
\hline Q5 & School's vision key to improvement plan & \multicolumn{2}{|c|}{$16 / 37.2$} & \multicolumn{2}{|c|}{$20 / 46.5$} & \multicolumn{2}{|c|}{$7 / 16.3$} & \multicolumn{2}{|c|}{$0 / 0$} & 3.2 & 43 \\
\hline \multirow[t]{2}{*}{ Q6 } & Faculty and staff are motivated by vision. & \multicolumn{2}{|c|}{$10 / 23.3$} & \multicolumn{2}{|c|}{$27 / 62.8$} & \multicolumn{2}{|c|}{$5 / 11.6$} & \multirow{2}{*}{\multicolumn{2}{|c|}{$1 / 2.3$}} & 3.1 & 43 \\
\hline & & & & \multicolumn{4}{|c|}{ Average Mean Score } & & & 3.2 & \\
\hline
\end{tabular}

Unlike the school's established vision and mission, the descriptive data (See Table 3) yield an observed average mean score 2.8 for work environment, which suggest a they were not totally happy with their work environment, which further suggest faculty and staff's disposition toward their work environment was unfavorable and thereby, answers research question (2). This same contrast occurred (See Table 4 and 5) when an observed average mean score of 2.9 for communication and 2.8 for administration suggesting faculty and staff were not completely satisfied with levels of school communications and administrative leadership, which answers research questions 3 and 4 respectively.

Table 3

\begin{tabular}{|c|c|c|c|c|c|c|c|}
\hline \multirow{2}{*}{\multicolumn{2}{|c|}{$\begin{array}{l}\text { Questions } \\
\text { Work Environment }\end{array}$}} & SA-4 & A-3 & D-2 & SD-1 & \multirow[b]{2}{*}{ Mean } & \multirow[b]{2}{*}{$\mathrm{N}$} \\
\hline & & \begin{tabular}{l|l}
$\mathrm{n}$ & $\%$ \\
\end{tabular} & \begin{tabular}{l|l|}
$\mathrm{n}$ & $\%$ \\
\end{tabular} & \begin{tabular}{l|l}
$\mathrm{n}$ & $\%$ \\
\end{tabular} & \begin{tabular}{l|l}
$\mathrm{n}$ & $\%$ \\
\end{tabular} & & \\
\hline Q7 & My input is valued. & $14 / 32.6$ & $19 / 44.2$ & $8 / 18.6$ & $2 / 4.7$ & 3 & 43 \\
\hline Q8 & Knowledge and information sharing is common. & $12 / 27.9$ & $18 / 41.9$ & $10 / 23.3$ & $3 / 7$ & 2.9 & 43 \\
\hline Q9 & Faculty and staff consult each other. & $11 / 25.6$ & $24 / 55.8$ & $5 / 11.6$ & $2 / 4.7$ & 3.1 & 43 \\
\hline Q10 & Individual contributions are appreciated. & $15 / 34.9$ & $24 / 55.8$ & $3 / 7$ & $1 / 2.3$ & 3.2 & 43 \\
\hline Q11 & When disagreements occur they are addressed. & $10 / 23.3$ & $15 / 34.9$ & $12 / 27.9$ & $6 / 14$ & 2.6 & 43 \\
\hline Q12 & Opinions are valued. & $11 / 25.6$ & $20 / 46.5$ & $9 / 20.9$ & $3 / 7$ & 2.9 & 43 \\
\hline Q13 & Faculty and staff morale is high. & $1 / 2.3$ & $13 / 30.2$ & $20 / 46.5$ & $9 / 20.9$ & 2.1 & 43 \\
\hline Q14 & Controversial issues are explored. & $9 / 20.9$ & $15 / 34.9$ & $15 / 34.9$ & $4 / 9.3$ & 2.7 & 43 \\
\hline Q15 & Faculty and staff model good behavior. & $7 / 16.3$ & $26 / 60.5$ & $10 / 23.3$ & $0 / 0$ & 2.9 & 43 \\
\hline Q16 & Faculty accomplish their jobs with enthusiasm. & $7 / 16.3$ & $20 / 46.5$ & $15 / 34.9$ & $1 / 2.3$ & 2.8 & 43 \\
\hline & & & Average & ean Score & & 2.8 & \\
\hline
\end{tabular}

Table 4

\begin{tabular}{|c|c|c|c|c|c|c|c|c|c|c|c|}
\hline \multirow{2}{*}{\multicolumn{2}{|c|}{$\begin{array}{l}\text { Questions } \\
\text { Communication }\end{array}$}} & \multicolumn{2}{|c|}{ SA-4 } & \multicolumn{2}{|c|}{ A-3 } & \multicolumn{2}{|c|}{ D-2 } & \multicolumn{2}{|l|}{ SD-1 } & \multirow[b]{2}{*}{ Mean } & \multirow[b]{2}{*}{$\mathrm{N}$} \\
\hline & & $\mathrm{n}$ & $\%$ & $\mathrm{n}$ & $\%$ & $\mathrm{n}$ & $\%$ & $\mathrm{n}$ & $\%$ & & \\
\hline Q17 & Principal places high priority on communications. & \multicolumn{2}{|c|}{$9 / 20.9$} & \multicolumn{2}{|c|}{$23 / 53.5$} & \multicolumn{2}{|c|}{$9 / 20.9$} & \multicolumn{2}{|c|}{$2 / 4.7$} & 2.9 & 43 \\
\hline Q18 & Principal models good communications skills. & \multicolumn{2}{|c|}{$9 / 20.9$} & \multicolumn{2}{|c|}{$17 / 39.5$} & \multicolumn{2}{|c|}{$14 / 32.6$} & \multicolumn{2}{|l|}{$3 / 7$} & 2.7 & 43 \\
\hline Q19 & Feedback is prompt and accurate. & \multicolumn{2}{|c|}{$8 / 18.6$} & \multicolumn{2}{|c|}{$19 / 44.2$} & \multicolumn{2}{|c|}{$15 / 34.9$} & \multicolumn{2}{|l|}{$1 / 2.3$} & 2.8 & 43 \\
\hline \multirow[t]{2}{*}{ Q20 } & Information sharing occurs often. & \multicolumn{2}{|c|}{$9 / 20.9$} & \multicolumn{2}{|c|}{$16 / 37.2$} & \multicolumn{2}{|c|}{$15 / 34.9$} & \multicolumn{2}{|l|}{$2 / 4.7$} & 3.4 & 43 \\
\hline & & & & \multicolumn{6}{|c|}{ Average Mean Score } & 2.9 & \\
\hline
\end{tabular}


Table 5

\begin{tabular}{|c|c|c|c|c|c|c|c|c|c|c|c|}
\hline \multirow{2}{*}{\multicolumn{2}{|c|}{$\begin{array}{l}\text { Questions } \\
\text { Administration }\end{array}$}} & \multicolumn{2}{|c|}{ SA-4 } & \multicolumn{2}{|c|}{ A-3 } & \multicolumn{2}{|c|}{ D-2 } & \multicolumn{2}{|c|}{ SD-1 } & \multirow[b]{2}{*}{ Mean } & \multirow[b]{2}{*}{$\mathrm{N}$} \\
\hline & & $\mathrm{n}$ & $\%$ & $\mathrm{n}$ & $\%$ & $\mathrm{n}$ & $\%$ & $\mathrm{n}$ & $\%$ & & \\
\hline $\mathrm{Q} 21$ & Principal is highly respected by everyone. & \multicolumn{2}{|c|}{$6 / 14$} & \multicolumn{2}{|c|}{$10 / 23.3$} & \multicolumn{2}{|c|}{$20 / 46.5$} & \multicolumn{2}{|c|}{$7 / 16.3$} & 2.3 & 43 \\
\hline Q22 & Principal is friendly and approachable. & \multicolumn{2}{|c|}{$17 / 39.5$} & \multicolumn{2}{|c|}{$17 / 39.5$} & \multicolumn{2}{|c|}{$9 / 20.9$} & \multicolumn{2}{|c|}{$0 / 0$} & 3.2 & 43 \\
\hline Q23 & Principal models the way. & \multicolumn{2}{|c|}{$14 / 32.6$} & \multicolumn{2}{|c|}{$18 / 41.9$} & \multicolumn{2}{|c|}{$9 / 20.9$} & \multicolumn{2}{|c|}{$2 / 4.7$} & 3 & 43 \\
\hline Q24 & Principal distributes resources fairly. & \multicolumn{2}{|c|}{$14 / 32.6$} & \multicolumn{2}{|c|}{$23 / 53.5$} & \multicolumn{2}{|c|}{$4 / 9.3$} & \multicolumn{2}{|c|}{$2 / 4.7$} & 3.1 & 43 \\
\hline Q25 & Principal treats faculty fairly and with respect. & \multicolumn{2}{|c|}{$14 / 32.6$} & \multicolumn{2}{|c|}{$18 / 41.9$} & \multicolumn{2}{|c|}{$9 / 20.9$} & \multicolumn{2}{|c|}{$2 / 4.7$} & 3 & 43 \\
\hline Q26 & Faculty clearly understand their role. & \multicolumn{2}{|c|}{$12 / 27.9$} & \multicolumn{2}{|c|}{$19 / 44.2$} & \multicolumn{2}{|c|}{$10 / 23.3$} & \multicolumn{2}{|c|}{$2 / 4.7$} & 2.9 & 43 \\
\hline Q27 & Principal does not show favoritism. & \multicolumn{2}{|c|}{$8 / 18.6$} & \multicolumn{2}{|c|}{$14 / 32.6$} & \multicolumn{2}{|c|}{$16 / 37.2$} & \multicolumn{2}{|c|}{$5 / 11.6$} & 2.5 & 43 \\
\hline \multirow[t]{2}{*}{ Q28 } & Principal monitors school by wandering around. & \multicolumn{2}{|c|}{$22 / 51.2$} & \multicolumn{2}{|c|}{$14 / 32.6$} & & & 0 & & 3.3 & 43 \\
\hline & & & & & rage & 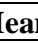 & cor & & & 2.8 & \\
\hline
\end{tabular}

\section{Analysis of Personal Opinion Questions}

There were 27 responses to Q29 and all responses fell well within the established response criteria (See Table 6). Consequently, the responses to Q29 were broken down in to three categories, 10 or $37 \%$ thought their work environment needed changing, 6 or $22 \%$ thought their pedagogy was impacted by the school climate, and 11 or $41 \%$ lodged general concerns regarding the school.

Question 30 asked respondents to rank their overall work environment from 1 to 10 , with 10 being the highest. This section yielded a mean score of 6.37, which suggests a near split down the middle of the scale (See Table 6). Question 31 ask respondents to compare the current school climate as controlled or influenced by administration for the past three school terms. There were 40 responses and all fell well within the established response criteria. The responses were broken down into three categories, 17 or $42 \%$ thought the current climate was better, 6 or $15 \%$ thought administration was a positive factor, and 23 or $56 \%$ thought administration was a negative factor. The responses to questions 30 and question 31 also suggest faculty and staff were not completely satisfied with their work environment and school climate, thereby supports the mean score in Table 2.

Table 6

Descriptive Analysis Table for Personal Opinion

Q30: At this time if you could rank your overall work environment from 1 - 10, with 10 being the highest.

\begin{tabular}{|c|c|c|c|c|c|c|c|c|c|c|c|}
\hline \multicolumn{12}{|c|}{ Ranking } \\
\hline 1 & 2 & 3 & 4 & 5 & 6 & 7 & 8 & 9 & 10 & & \\
\hline $\mathrm{n} / \%$ & $\mathrm{n} / \%$ & $\mathrm{n} / \%$ & $\mathrm{n} / \%$ & $\mathrm{n} / \%$ & $\mathrm{n} / \%$ & $\mathrm{n} / \%$ & $\mathrm{n} / \%$ & $\mathrm{n} / \%$ & $\mathrm{n} / \%$ & Mean & $\mathrm{N}$ \\
\hline $3 / 7$ & $3 / 7$ & $3 / 7$ & $0 / 0$ & $5 / 11.6$ & $6 / 14$ & $5 / 11.6$ & $6 / 14$ & $8 / 18.6$ & $4 / 9.3$ & 6.372 & 43 \\
\hline
\end{tabular}

\section{Rasch Item Analysis}

Rasch Measurement Theory offers another way to analyze the responses to the Climate Survey (Bond \& Fox, 2001; Wilson, 2005). The Rasch Measurement Model is a mathematical model that produces an interval measure for each person and for each item on a common scale with items centered at 0 as shown on the left in Table 7. The more satisfied the person is with the school climate, the higher the person score. The easier it is to respond positively to a survey item, the higher the item score. For example, survey question 13 receives the lowest score; in other words, the group is least likely to agree with statement "Faculty and staff morale is high." The next lowest score is associated with the statement "Principal is highly respected by everyone." On the other hand, survey questions 4 and 28 receive the highest scores; so the group is most likely to agree with the statement "Motivated by the school vision to do my best" and "Principal monitors school by wandering around." Person 24 was the least satisfied of the group and person 42 was the most satisfied. Persons 42, 20, 6, 9, and 15 expressed the greatest satisfaction overall, quite separate from the rest of the people. Persons 28 and 24 were the least satisfied. 
The scale ranges from -5 to 5 logits. "Logits" stands for "log odds units" and reflects the fact that the Rasch model is a probabilistic model. If the person measure is the same as the item measure, then there is a 50/50 chance that the person will agree vs. disagree with the item. For example, persons 31, 35, and 36 have a 50/50 chance of agreeing or disagreeing with survey questions 8,12 , and 17 . On the other hand, there is a very high probability that persons 31,35 , and 36 would agree with statements 21 and 13 since those item measures are far below the person measures on the scale. There is a very high probability that they would NOT agree with statements 4 and 28 . In other words, the distance between person and item measures on the scale dictates the likelihood that a person would agree or disagree with the item.

The variable map shown in Table 7 was produced by the software Facets (Linacre, 2005) using the Rating Scale Rasch Model that accommodates a rating scale of 1 to 4 . Fit statistics showed very good model fit, especially good with a sample size of only 43. Infit and outfit statistics for both persons and items were all within ranges recommended by Bond and Fox (2001, p. 179).

Table 7

FASCH ANALYSIS

Higher Score Greater Satisfaction

| ITEMS | PEOPLE

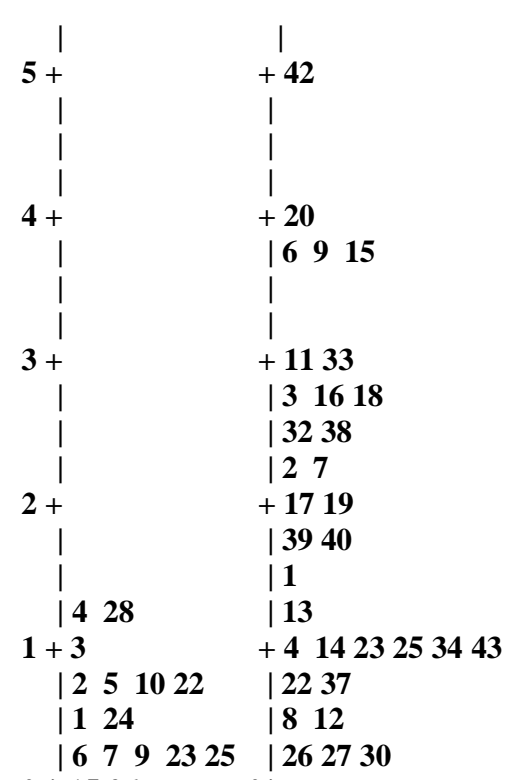

$0 * 1526 \quad 0 *$

\begin{tabular}{|l|l|l|l|}
81217 & 313536
\end{tabular}

| $16181920 \quad 1021$

\begin{tabular}{l|l}
1114 & 41
\end{tabular}

$-1+27+5$

| 29

21

$-2+\quad+28$

| 13

\begin{tabular}{l|l}
$\mid$ & +24
\end{tabular}

| 1

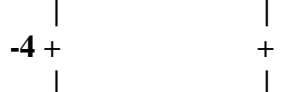

Lower Score Lower Satisfaction 
Standard errors for the item measures ranged from .25 to .28 . Standard errors for the person measures ranged from .30 to .43 , with one outlier at .63 for person 42. Ideally, the distribution of person measures and item measures should spread across the same scale. However, in the Climate Survey the items extend over a range from approximately -3 to 2 while the persons extend over a range from -5 to 5 . This indicates that the survey might be improved by adding some statements to cover extreme satisfaction as well as extreme dissatisfaction.

\section{Discussions And Recommendations}

The results of this study suggest that the school climate may be in an early toxic state which appears to show early stages of a negative impact on student performance. The challenge for Shane's principal is to provide the leadership needed to achieve basic levels of competence and then to transcend this competence to get extraordinary commitment and performance from self-motivated faculty. This may require additional training and/or assistance for the principal, and will most certainly require that areas of concern noted by respondents be addressed. It is recommended that improvement efforts be monitored to ensure that faculty input is valued. It is further recommended that the principal concentrate on building a better environment by providing the climate and interpersonal support that enhances faculty and staff opportunities for fulfillment of individual needs for achievement, responsibility, competence, and esteem. Once a positive climate is established, attention should then be focused on working to bind and bond the faculty into a cohesive group focused on achievement of common goals.

The findings also suggest a lack of faculty and staff respect for administration, a hostile work environment, and overall low morale. Evidence was apparent throughout the survey of a deep frustration among faculty and staff. Although responses to work environment and administration, were split along mean scores, the overall data indicate that the status quo cannot continue without negative consequences. When half of the faculty and staff are negative about their work environment and administration, teaching and learning is almost certain to be negatively impacted. These disparities are not just in whether working conditions are present, but whether or not school leadership makes efforts to improve them. Faculty and staff who want to stay in their schools are far more likely than those who want to move to believe that school leadership is working toward improvement. The Rasch instrument further supports the recommendations. School improvement is not possible without skilled, knowledgeable leadership that is responsive to the needs of all teachers and students. These factors are also supported by the Wallace Foundation (2004). During a 2004 symposium they revealed that leadership is essential for developing and retaining a quality work environment, and across states where climate surveys were conducted, faculty and staff consistently rank leadership as the most important factor affecting their work environment at school.

\section{AUTHOR INFORMATION}

J. Eric Tubbs, author, is Assistant Professor of Educational Leadership in the Bagwell College of Education at Kennesaw State University. He is a former high school and middle school principal. He has leadership experience in state government, private industry and business. Dr. Tubbs received his B. S. degree from The University of Akron, M. A. from California State University, Los Angeles, Ed. S. from Converse College, and obtained his Ed. D. in Educational Leadership from The University of Sarasota Florida. Dr. Tubbs has additional specialized training in school improvement, curriculum and instruction, the superintendency, quantitative research, and other areas of leadership. Dr. Tubbs also served as graduate field experience program coordinator for the Department of Educational Leadership.

\section{REFERENCES}

1. Ashby, Dianne E., and Krug, Samuel E. (1998). Understanding and Promoting School Climate and Culture, In Dianne E. Ashby and Samuel Krug (Eds.), Thinking Through the Principalship. New York: Eye on Education Inc.

2. Bond, T.G. and Fox, C.M. (2001). Applying the Rasch Model. Fundamental Measurement in the Human Sciences. Mahwah, New Jersey: Lawrence Erlbaum Associates. 
3. Christensen, C., Marx, M., and Stevenson, H. H. (2006, October). The tools of cooperation and change. Harvard Business Review, 84 (10), 72-80.

4. Ehman, L. (1980). The American school in the political socialization process. Review of Educational Research. 50 99-119.

5. Freiberg, H. J. (1998). Measuring school climate: Let me count the ways. Educational Leadership, 56(1), 22-26.

6. Griffith, James (2000). "School Climate as Group Evaluation and Group Consensus: Student and Parent Perceptions of the Elementary School Environment." The Elementary School Journal 101(1): 35-61.

7. Halpin, A. W. and Croft, D. B. (1963). The organizational climate of schools. Chicago: Midwest Administration Center of the University of Chicago.

8. Keefe, J. W. and Kelley, E. A. (1990). Comprehensive assessment and school improvement. National Association of Secondary School Principals. NASSP Bulletin, 74(530), 54-63.

9. Kuperminc, G. P., Leadbeater, B. J. and Blatt, S. J. (2001). School social climate and individual differences in vulnerability to psychopathology among middle school students. Journal of School Psychology, 39(2), 141-159.

10. Linacre, J.M. (2005). Facets (Version 3.57) [Computer program]. Chicago: MESA press.

11. McDill, Edward L., Leo C. Rigsby, and Meyers, Edmund D.. (1969). "Educational Climates of High Schools: Their Effects and Sources." The American Journal of Sociology 32 (2): 567-586.

12. McEvoy, A. and Welker, R. (2000). Antisocial behavior, academic failure, and school climate: A critical review. Journal of Emotional and Behavioral Disorders, 8(3), 130- 140.

13. Peterson, R.L. and Skiba, R. (2001). Creating school climates that prevent school violence. The Clearing House, 74(3), 155-163.

14. Wilson, M. (2005). Constructing Measures. An Item Response Modeling Approach. Mahwah, New Jersey: Lawrence Erlbaum Associates. 